\title{
Electron Impact Ionization of Air Molecules and Its Application to the Abatement of Volatile Organic Compounds
}

B. M. Penetrante
M. C. Hsiao
J. N. Bardsley
B. T. Merritt
G. E. Vogtlin
P. H. Wallman
A. Kuthi
C. P. Burkhart
J. R. Bayless

This paper was prepared for submittal to the NATO Advanced Study Institute on Molecular Physics and Hypersonic Flows Maratea, Italy

May 21 - June 3, 1995

May 21, 1995

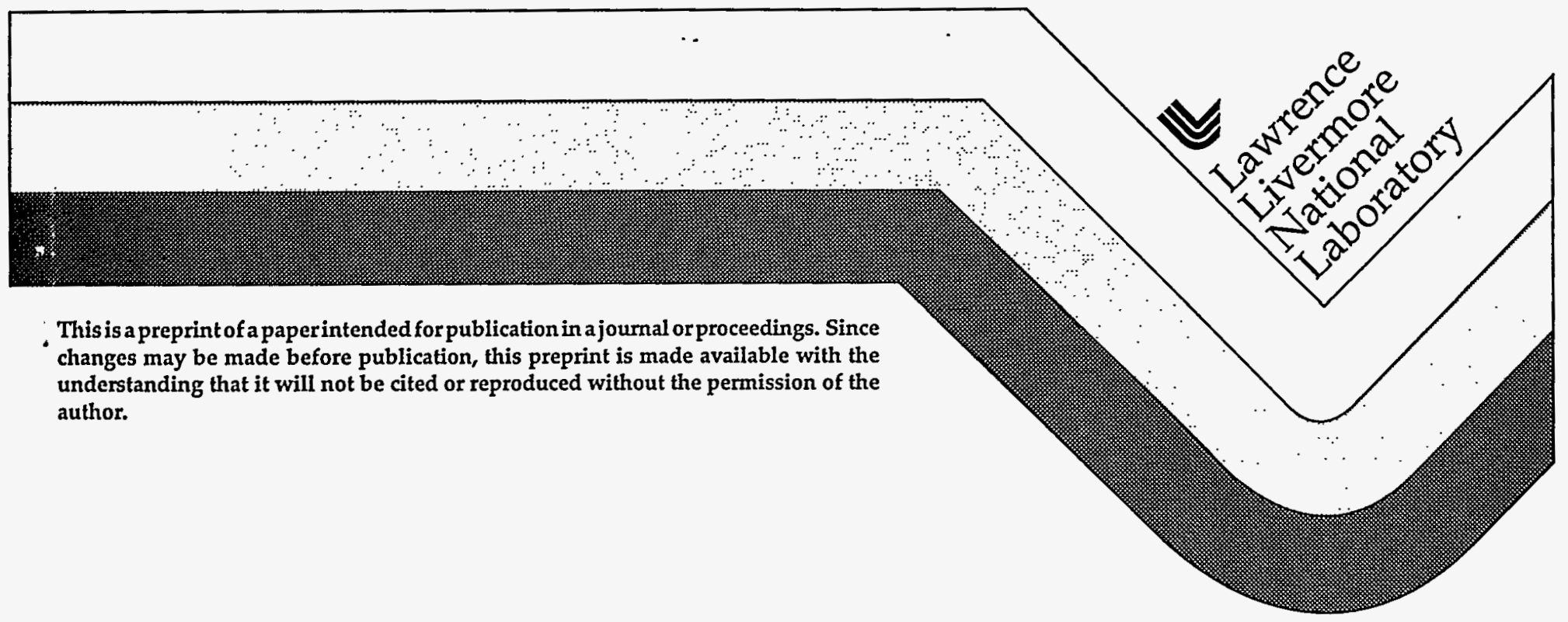

This is a preprint of a paperintended for publication in a journal or proceedings. Since changes may be made before publication, this preprint is made available with the understanding that it will not be cited or reproduced without the permission of the author. 


\section{DISCLAIMER}

This document was prepared as an account of work sponsored by an agency of the United States Government. Neither the United States Government nor the University of California nor any of their employees, makes any warranty, express or implied, or assumes any legal liability or responsibility for the accuracy, completeness, or usefulness of any information, apparatus, product, or process disclosed, or represents that its use would not infringe privately owned rights. Reference herein to any specific commercial product, process, or service by trade name, trademark, manufacturer, or otherwise, does not necessarily constitute or imply its endorsement, recommendation, or favoring by the United States Government or the University of California. The views and opinions of authors expressed herein do not necessarily state or reflect those of the United States Government or the University of California, and shall not be used for advertising or product endorsement purposes.

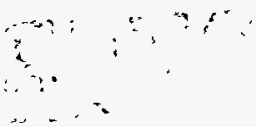


NATO Advanced Study Institute on Molecular Physics and Hypersonic Flows 21 May - 3 June 1995, Maratea; Italy

\title{
ELECTRON-IMPACT IONIZATION OF AIR MOLECULES AND ITS APPLICATION TO THE ABATEMENT OF VOLATILE ORGANIC COMPOUNDS
}

\author{
B. M. Penetrante, M. C. Hsiao, J. N. Bardsley, \\ B. T. Merritt, G. E. Vogtlin and P. H. Wallman \\ Lawrence Livermore National Laboratory, Livermore, California 94550 \\ A. Kuthi, C. P. Burkhart and J. R. Bayless \\ First Point Scientific, Inc., Agoura Hills, California 91301
}

\section{INTRODUCTION}

Volatile organic compounds (VOCs) are emitted from manufacturing the multitude of consumer products used every day. In most manufacturing processes, either for the raw materials, intermediates, or the finished product, VOC-containing materials are present as chemicals, solvents, release agents, coatings, and decomposition products that eventually must be disposed. In manufacturing, there is usually a gaseous effluent that contains low concentrations of organics and is vented into the atmosphere. Chlorinated VOCs are some of the most common solvents used, and are now found in hazardous concentrations at many industrial and government installations. Cost effective technologies for disposal of VOCs are therefore being sought by government and by industry, and there is a need for reliable data concerning the decomposition mechanisms associated with these compounds. Non-thermal plasma methods using electrical discharges and electron beams are some of the emerging technologies for the disposal of these toxic substances. The electron beam method has been applied to the removal of vinyl chloride [1], trichloroethylene [2-3], carbon tetrachloride [4-6] and other types of volatile hydrocarbons from industrial offgases [7]. Some of the electrical discharge reactors that have been investigated for VOC abatement include the pulsed corona [8-10], ferroelectric packed bed [9-10] dielectricbarrier discharge [11-17], surface discharge [18-19], gliding arc [20-21] and microwave [22].

There are many types of non-thermal plasma techniques that are being investigated for VOC abatement applications. The basic principle that these techniques have in common is to produce a plasma in which a majority of the electrical energy goes into the production of energetic electrons, rather than into gas heating. Through electron-impact dissociation and ionization of the background gas molecules, the energetic electrons produce free radicals and electron-ion pairs that, in turn, decompose the VOC molecules. Whatever the type of reactor, the plasma can induce three basic types of reactions with the VOC molecules, as shown in Fig. 1. Electron-impact dissociation of oxygen molecules produces $\mathrm{O}$ (and $\mathrm{OH}$ radicals in the presence of water vapor) that could oxidize the VOC molecules. Electron-impact ionization of the background air molecules produces electron-ion pairs. The electrons could decompose the VOC molecules via dissociative electron attachment. 
The ions could decompose the VOC molecules via dissociative charge exchange. The decomposition pathway for a particular VOC depends on the reaction rate constants and the amount of radicals and electron-ion pairs produced in the plasma.

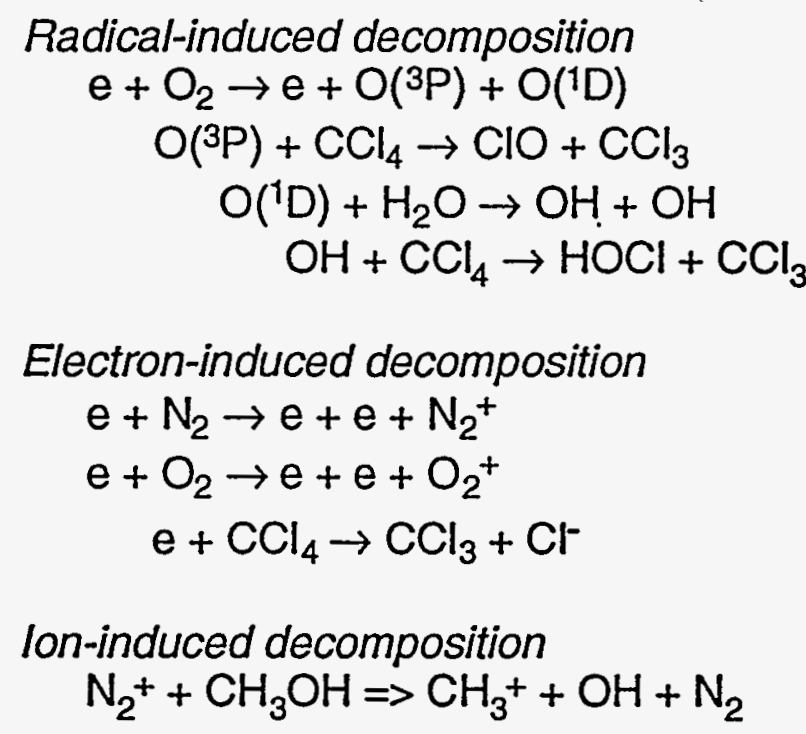

Fig. 1. There are three basic types of chemical reactions responsible for the decomposition of volatile organic compounds: (a) decomposition via oxidation by $\mathrm{O}$ and $\mathrm{OH}$ free radicals or reduction by $\mathrm{N}$ atoms, (b) electron-induced decomposition via dissociative electron attachment, and (c) ion-induced decomposition via dissociative charge exchange.

The electron mean energy in a plasma reactor is very important because it determines the types of radicals produced in the plasma and the input electrical energy required to produce those radicals. Fig. 2 shows the dissipation of the input electrical power in a dry air discharge. Note that at low electron mean energies $(<5 \mathrm{eV})$ a large fraction of the input electrical energy is consumed in the vibrational excitation of $\mathrm{N}_{2}$. Electron mean energies around $5 \mathrm{eV}$ are optimum for the electron-impact dissociation of $\mathrm{O}_{2}$, which is important for the production of $\mathrm{O}$ radicals. High electron mean energies are required to efficiently implement the dissociation of $\mathrm{N}_{2}$. For VOCs that take advantage of electron-induced or ion-induced decomposition, high electron mean energies are required to efficiently implement the ionization of the background gas.

In terms of the electron energy distribution in the plasma, there are basically only two types of non-thermal atmospheric-pressure plasma reactors: electrical discharge reactors and electron beam reactors. Electrical discharge techniques can be implemented in many ways, depending on the electrode configuration and electrical power supply (pulsed, $A C$ or DC). Two of the more extensively investigated types of electrical discharge reactors are the pulsed corona and the dielectric-barrier discharge, shown in Fig. 3. In the pulsed corona method, the reactor is driven by very short pulses of high voltage, thus creating short-lived discharge plasmas that consist of energetic electrons, which in turn produce the radicals responsible for the decomposition of the undesirable molecules. In a dielectric barrier discharge reactor, one or both of the electrodes are covered with a thin dielectric 
layer, such as glass or alumina. Dielectric-barrier discharge reactors, also referred to as silent discharge reactors, are now routinely used to produce commercial quantities of ozone. Whereas in the pulsed corona method the transient behavior of the plasma is controlled by the applied voltage pulse, the plasma that takes place in a dielectric-barrier discharge self-extinguishes when charge build-up on the dielectric layer reduces the local electric field.

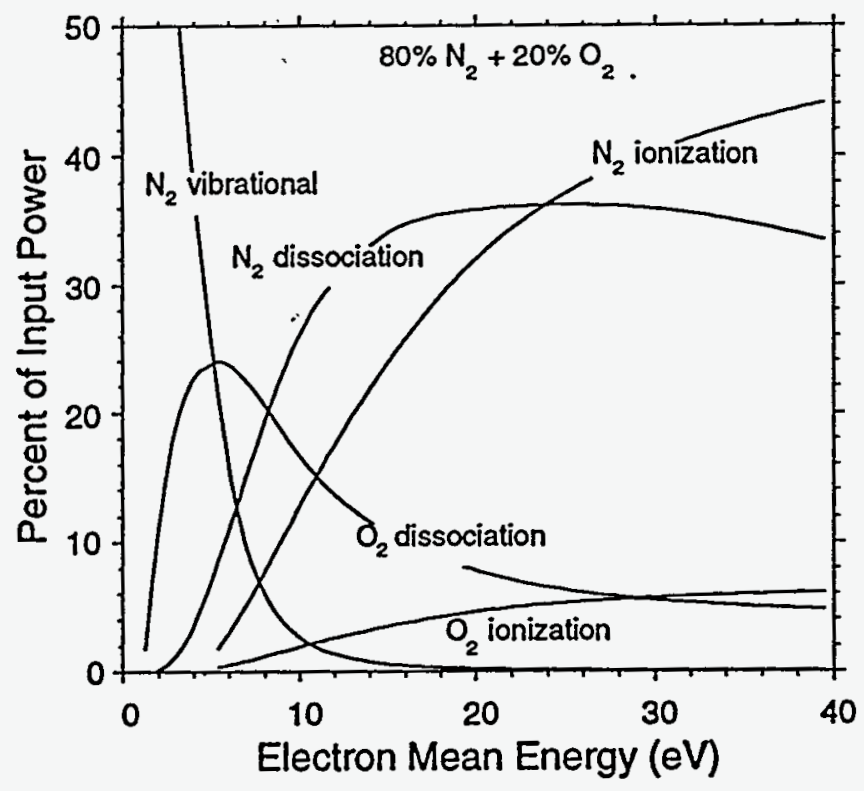

Fig. 2. Power dissipation in a dry air discharge, showing the percent of input power consumed in the electron-impact processes leading to vibrational excitation, dissociation and ionization of $\mathrm{N}_{2}$ and $\mathrm{O}_{2}$.

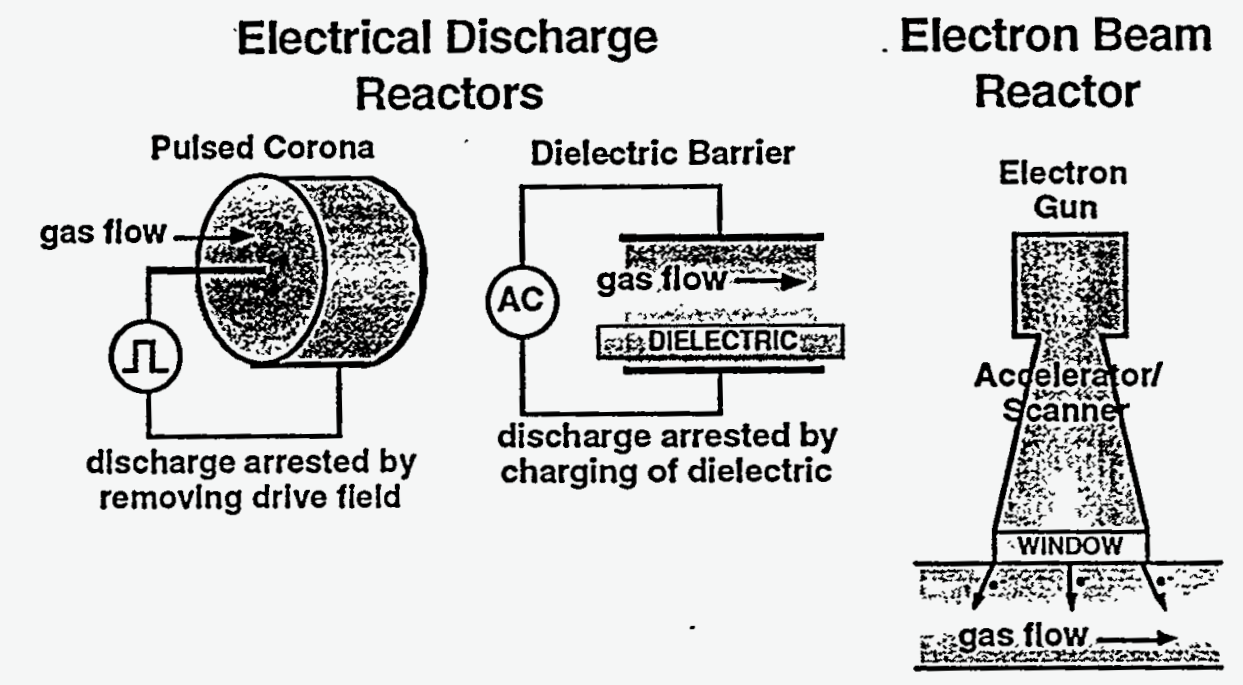

Fig. 3. There are basically two types of non-thermal atmospheric-pressure plasma reactors: electrical discharge reactors and electron beam reactors. 
In this paper we present data on the non-thermal plasma processing of two representative VOCs: carbon tetrachloride and methanol. The investigation used a compact electron beam reactor, and two types of discharge reactors: a pulsed corona and a dielectricbarrier discharge. To the knowledge of the authors, this is the first comparison of the energy efficiency of electron beam, pulsed corona and dielectric-barrier discharge processing of these VOCs under identical gas conditions. For most electrical discharge reactors our analysis suggests that the attainable electron mean energy is rather limited and cannot be significantly enhanced by changing the electrode configuration or voltage waveform. Our experimental data confirms that there is no significant difference in the performance of our pulsed corona and dielectric-barrier discharge reactors. We observe that electron beam processing is remarkably more energy efficient than electrical discharge processing in decomposing either of these VOC molecules. During electron beam processing, the specific energy consumption is consistent with the energy required for the ionization of the background air molecules. For carbon tetrachloride, the dominant decomposition pathway is dissociative electron attachment. For methanol, the dominant decomposition pathway is dissociative charge exchange.

\section{TEST FACILITY}

All of our experiments were performed in a flow-through configuration. To characterize the energy consumption of the process for each VOC, the composition of the effluent gas was recorded as a function of the input energy density. The input energy density, Joules per standard liter, is the ratio of the power (deposited into the gas) to gas flow rate at standard conditions $\left(25^{\circ} \mathrm{C}\right.$ and $\left.1 \mathrm{~atm}\right)$. The amount of VOC was quantified an FTIR analyzer and a gas chromatograph/mass spectrometer.

Our electron beam reactor used a cylindrical electron gun designed to deliver a cylindrically symmetric electron beam that is projected radially inward through a $5 \mathrm{~cm}$ wide annular window into a $17 \mathrm{~cm}$ diameter flow duct. An electron beam of $125 \mathrm{keV}$ energy was introduced into the reaction chamber through a 0.7 mil thick titanium window. The electron beam current was produced from a low-pressure helium plasma in an annular vacuum chamber surrounding the flow duct.

Our pulsed corona reactor is a $1.5 \mathrm{~mm}$ diameter wire in a $60 \mathrm{~mm}$ diameter metal tube $300 \mathrm{~mm}$ long. The power supply is a magnetic pulse compression system capable of delivering up to $15-35 \mathrm{kV}$ output into $100 \mathrm{~ns}$ FWHM pulses at repetition rates from $15 \mathrm{~Hz}$ to $1.5 \mathrm{kHz}$. The power input to the processor was varied by changing either the pulse energy or pulse repetition frequency. For the same energy density input, either method produced almost identical results. The gas mixtures were set with mass flow controllers. The gas and processor temperatures can be maintained at a temperature that can be controlled from $25^{\circ} \mathrm{C}$ to $300^{\circ} \mathrm{C}$.

The dielectric-barrier discharge electrode structure has a similar electrode structure except that it has a dielectric material on the inside surface of the outer tube electrode. It consists of a $1.5 \mathrm{~mm}$ diameter wire in a $290 \mathrm{~mm}$ long alumina tube with inner and outer diameters of $53 \mathrm{~mm}$ and $58 \mathrm{~mm}$, respectively. The middle $170 \mathrm{~mm}$ of the dielectric tube has aluminum foil coating the outside to form the other electrode. 


\section{ELECTRON AND CHEMICAL KINETICS}

To calculate the ion and radical production yields by electrical discharge processing, we used the Boltzmann code ELENDIF [23] to calculate electron energy deposition. ELENDIF uses as input the specified gas composition and the electron-molecule collision cross sections. To calculate the ion and radical production yields by electron beam processing, we used the code DEGRAD [24]. DEGRAD also uses as input the specified gas composition and the electron-molecule collision cross sections. This code follows typical electrons as they perform successive collisions, and discrete energy bins are used to represent the energy degradation of an electron from a given beam energy. The procedure records the number of excitations, dissociations and ionizations, and the total number of all orders of secondary electrons. The chemical kinetics describing the subsequent interaction of the ions and radicals with the exhaust gas was studied using CHEMKIN-II [25].

\section{RESULTS}

In discharge processing, the rate coefficients for electron-impact dissociation and ionization reactions strongly depend on the electron mean energy in the discharge plasma. In pulsed corona and dielectric-barrier discharge reactors, the non-thermal plasma is produced through the formation of statistically distributed microdischarges. The electrons dissociate and ionize the background gas molecules within nanoseconds in the narrow channel formed by each microdischarge. The electron energy distribution in the plasma is complicated because the electric field is strongly non-uniform (e.g. because of strong space-charge field effects) and time dependent. However, most of the species responsible for the chemical processing are generated in the microdischarge channels already established during the main current flow. In each microdischarge column, the electrons acquire a drift velocity, $v_{d}$, and an average energy corresponding to an effective $E / n$, i.e., the value of the electric field $E$ divided by the total gas density $n$. The efficiency for a particular electron-impact process can be expressed in terms of the $G$-value (number of dissociation or ionization reactions per $100 \mathrm{eV}$ of input energy) defined as

$$
\mathrm{G} \text {-value }=100 \mathrm{k} /\left(\mathrm{v}_{\mathrm{d}} \mathrm{E} / \mathrm{n}\right)
$$

where $\mathrm{k}$ is the rate coefficient ( $\mathrm{cm}^{3} / \mathrm{molec}-\mathrm{s}$ ). The rate coefficient $\mathrm{k}$ represents the number of reactions in a unit volume per unit time. The quantity $v_{d} E / n$ represents the amount of energy expended by the electrons in a unit volume per unit time. In Fig. 4 the calculated Gvalues for various electron-impact dissociation and ionization processes in dry air are shown as functions of the electron mean energy in the discharge plasma.

Under most conditions encountered in pulsed corona or dielectric-barrier discharge processing, the effective $E / \mathrm{n}$ is close to the value for breakdown (Paschen field) [26-27]. For dry air, the effective $\mathrm{E} / \mathrm{n}$ is around $130 \mathrm{Td}\left(1 \mathrm{Td}=10^{-17} \mathrm{~V}-\mathrm{cm}^{2}\right)$, which corresponds to an electron mean energy of about $4 \mathrm{eV}$. This analysis suggests that the attainable electron mean energy is rather limited and cannot be significantly enhanced by changing the electrode configuration or voltage pulse parameters. Fig. 5 shows the comparison between pulsed corona and dielectric-barrier discharge processing of methanol in dry air at $120^{\circ} \mathrm{C}$. 


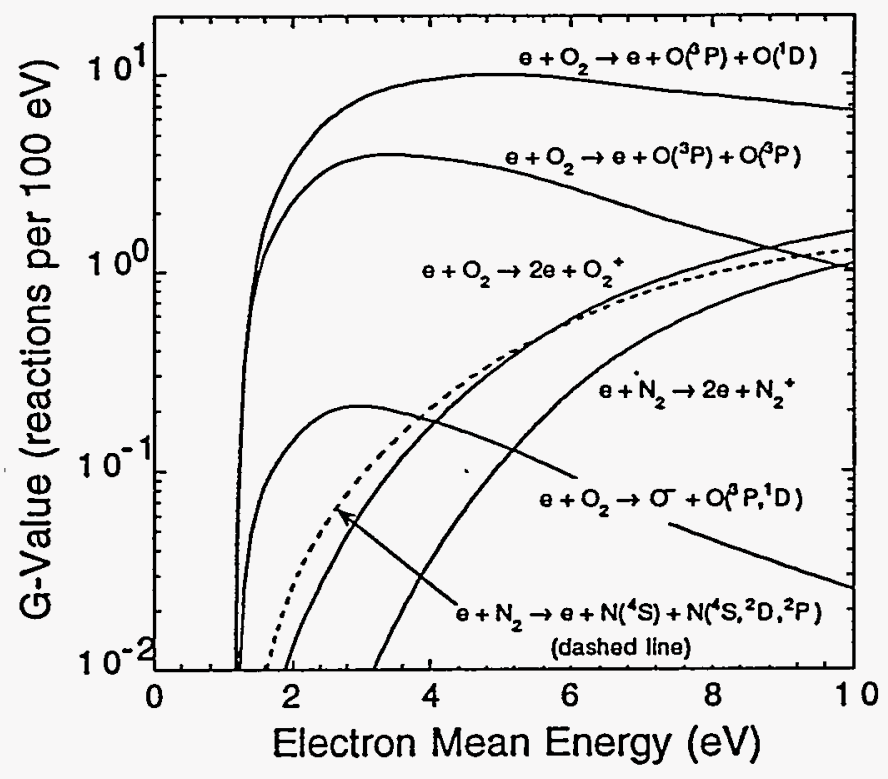

Fig. 4. Calculated G-values (number of reactions per $100 \mathrm{eV}$ of input energy) for dissociation and ionization processes in dry air, shown as functions of the electron mean energy in a discharge plasma.

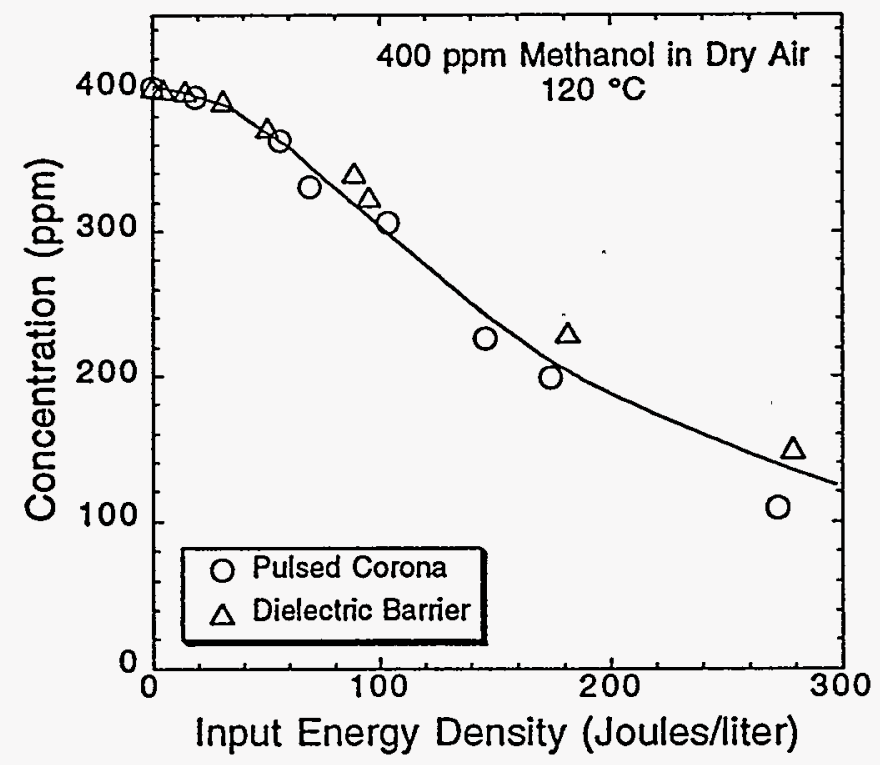

Fig. 5. Pulsed corona and dielectric-barrier discharge processing of $400 \mathrm{ppm}$ methanol in dry air at $120^{\circ} \mathrm{C}$. There is no significant difference in the performance of different types of electrical discharge reactors. 
Our experimental data confirms that there is no significant difference in the performance of pulsed corona and dielectric-barrier discharge reactors.

In electron beam processing, the efficiency for a particular electron-impact process can be expressed in terms of the G-value, which is defined in the code DEGRAD as

$$
\text { G-value }=100 \mathrm{~N}_{\mathrm{j}} / \mathrm{E}_{\mathrm{p}}
$$

where $N_{j}$ is the number of dissociation or ionization events, and $E_{p}$ is the primary electron energy.

Table 1 shows a comparison of the calculated G-values for dissociation processes in dry air using an electron beam and a discharge reactor. Discharge plasma conditions are optimum for the dissociation of $\mathrm{O}_{2}$. The production of $\mathrm{O}$ radicals is higher in a pulsed corona reactor compared to that in an electron beam reactor. Table 2 shows a comparison of the calculated G-values for ionization processes in dry air using an electron beam and a discharge reactor. The efficiency for production of electron-ion pairs is much higher in an electron beam reactor compared to that in a pulsed corona reactor.

Table 1. Calculated G-values (number of reactions per $100 \mathrm{eV}$ of input energy) for dissociation processes in dry air using an electron beam and an electrical discharge reactor.

\begin{tabular}{c|c|c}
\hline REACTION & Electron Beam & Discharge \\
\hline $\mathrm{e}+\mathrm{N}_{2} \rightarrow \mathrm{e}+\mathrm{N}\left({ }^{4} \mathrm{~S}\right)+\mathrm{N}\left({ }^{4} \mathrm{~S},{ }^{2} \mathrm{D},{ }^{2} \mathrm{P}\right)$ & 1.2 & 0.17 \\
\hline $\mathrm{e}+\mathrm{O}_{2} \rightarrow \mathrm{e}+\mathrm{O}\left({ }^{3} \mathrm{P}\right)+\mathrm{O}\left({ }^{3} \mathrm{P}\right)$ & 1.3 & 4.0 \\
\hline $\mathrm{e}+\mathrm{O}_{2} \rightarrow \mathrm{e}+\mathrm{O}\left({ }^{3} \mathrm{P}\right)+\mathrm{O}\left({ }^{1} \mathrm{D}\right)$ & 2.65 & 10.0 \\
\hline $\mathrm{e}+\mathrm{O}_{2} \rightarrow \mathrm{O}^{-}+\mathrm{O}\left({ }^{3} \mathrm{P},{ }^{1} \mathrm{D}\right)$ & 0.11 & 0.19 \\
\hline
\end{tabular}

Table 2. Calculated G-values (number of reactions per $100 \mathrm{eV}$ of input energy) for ionization processes in dry air using an electron beam and an electrical discharge reactor.

\begin{tabular}{c|c|c}
\hline REACTION & Electron Beam & Discharge \\
\hline $\mathrm{e}+\mathrm{N}_{2} \rightarrow 2 \mathrm{e}+\mathrm{N}\left({ }^{4} \mathrm{~S},{ }^{2} \mathrm{D}\right)+\mathrm{N}^{+}$ & 0.69 & $<10^{-6}$ \\
\hline $\mathrm{e}+\mathrm{N}_{2} \rightarrow 2 \mathrm{e}+\mathrm{N}_{2}{ }^{+}$ & 2.27 & 0.044 \\
\hline $\mathrm{e}+\mathrm{O}_{2} \rightarrow 2 \mathrm{e}+\mathrm{O}_{2}{ }^{+}$ & 2.07 & 0.17 \\
\hline $\mathrm{e}+\mathrm{O}_{2} \rightarrow 2 \mathrm{e}+\mathrm{O}\left({ }^{1} \mathrm{D}\right)+\mathrm{O}^{+}$ & 1.23 & 0.0016 \\
\hline
\end{tabular}

In non-thermal plasma processing of a mixture containing very dilute concentrations of VOC molecules, the input electrical energy is dissipated by the primary electrons mostly in interactions with the background gas molecules. The energetic primary electrons produce free radicals and electron-ion pairs through electron-impact dissociation and ionization. In a 
dry air mixture, electron-impact dissociation of molecular oxygen produces the ground state atomic oxygen $\mathrm{O}(\mathrm{P})$ and excited atomic oxygen $\mathrm{O}\left({ }^{\mathrm{I} D}\right)$ :

$$
\begin{aligned}
& \mathrm{e}+\mathrm{O}_{2} \rightarrow \mathrm{e}+\mathrm{O}\left({ }^{3} \mathrm{P}\right)+\mathrm{O}\left({ }^{3} \mathrm{P}\right) \\
& \mathrm{e}+\mathrm{O}_{2} \rightarrow \mathrm{e}+\mathrm{O}\left({ }^{3} \mathrm{P}\right)+\mathrm{O}\left({ }^{1} \mathrm{D}\right)
\end{aligned}
$$

In addition, with energetic electrons, $O\left({ }^{3} P\right)$ and $O\left({ }^{1} D\right)$ can be produced via two-body dissociative attachment:

$$
\mathrm{e}+\mathrm{O}_{2} \rightarrow \mathrm{O}^{-}+\mathrm{O}\left({ }^{3} \mathrm{P},{ }^{\mathrm{l} D}\right)
$$

As seen in Fig. 4 the main contribution to $\mathrm{O}$ radical production comes from the dissociation reactions (1a) and (1b).

The $\mathrm{O}$ radicals can dissociate $\mathrm{CCl}_{4}$ into $\mathrm{ClO}$ and $\mathrm{CCl}_{3}$ [28-30]:

$$
\begin{aligned}
& \mathrm{O}\left({ }^{3} \mathrm{P}\right)+\mathrm{CCl}_{4} \rightarrow \mathrm{ClO}+\mathrm{CCl}_{3} \\
& \mathrm{O}\left({ }^{1} \mathrm{D}\right)+\mathrm{CCl}_{4} \rightarrow \mathrm{ClO}+\mathrm{CCl}_{3}
\end{aligned}
$$

Another mechanism for the dissociation of $\mathrm{CCl}_{4}$ is through the secondary electrons. Electron-ion pairs are produced through various electron-impact ionization processes [3132]:

$$
\begin{aligned}
& \mathrm{e}+\mathrm{N}_{2} \rightarrow 2 \mathrm{e}+\mathrm{N}_{2}^{+} \\
& \mathrm{e}+\mathrm{N}_{2} \rightarrow 2 \mathrm{e}+\mathrm{N}\left({ }^{4} \mathrm{~S}\right)+\mathrm{N}^{+} \\
& \mathrm{e}+\mathrm{N}_{2} \rightarrow 2 \mathrm{e}+\mathrm{N}(2 \mathrm{D})+\mathrm{N}^{+} \\
& \mathrm{e}+\mathrm{O}_{2} \rightarrow 2 \mathrm{e}+\mathrm{O}_{2}^{+} \\
& \mathrm{e}+\mathrm{O}_{2} \rightarrow 2 \mathrm{e}+\mathrm{O}\left({ }^{1} \mathrm{D}\right)+\mathrm{O}^{+}
\end{aligned}
$$

The secondary electrons can dissociate $\mathrm{CCl}_{4}$ via dissociative electron attachment $[17,18]$ to produce $\mathrm{CCl}_{3}$ and a negative ion $\mathrm{Cl}^{-}$:

$$
\mathrm{e}+\mathrm{CCl}_{4} \rightarrow \mathrm{CCl}_{3}+\mathrm{Cl}^{-}
$$

The rate coefficient for reaction (9) is on the order of $10^{-7} \mathrm{~cm}^{3} /($ molec-s) [33-34]. The rate coefficient for reaction (3a) is less than $10^{-14} \mathrm{~cm}^{3} /($ molec-s) [28], while that for reaction (3b) is around $10^{-10} \mathrm{~cm}^{3} /($ molec-s) [29-30]. An examination of the G-values shown in Tables 1 and 2 indicates that dissociative electron attachment will dominate the initial decomposition of $\mathrm{CCl}_{4}$ for both electron beam and electrical discharge reactor conditions.

The charge exchange reaction of positive ions, such as $\mathrm{N}_{2}^{+}$, with the background $\mathrm{O}_{2}$ is fast, resulting in mostly $\mathrm{O}_{2}+$ ions [35]:

$$
\mathrm{N}_{2}^{+}+\mathrm{O}_{2} \rightarrow \mathrm{N}_{2}+\mathrm{O}_{2}{ }^{+}
$$


The positive ions react with $\mathrm{Cl}^{-}$through the ion-ion neutralization reaction to produce $\mathrm{Cl}$ and $O$ radicals:

$$
\mathrm{Cl}^{-}+\mathrm{O}_{2}^{+} \rightarrow \mathrm{Cl}+2 \mathrm{O}
$$

In the absence of scavenging reactions for $\mathrm{CCl}_{3}$, the input energy would be wasted because $\mathrm{Cl}$ and $\mathrm{CCl}_{3}$ would simply recombine quickly to reform the original pollutant [36-37]:

$$
\mathrm{Cl}+\mathrm{CCl}_{3}+\mathrm{M} \rightarrow \mathrm{CCl}_{4}+\mathrm{M}
$$

Fortunately, the presence of $\mathrm{O}_{2}$ scavenges the $\mathrm{CCl}_{3}$ through the fast reaction [38-39]:

$$
\mathrm{CCl}_{3}+\mathrm{O}_{2}+\mathrm{M} \rightarrow \mathrm{CCl}_{3} \mathrm{O}_{2}+\mathrm{M}
$$

The $\mathrm{CCl}_{3} \mathrm{O}_{2}$ species undergoes a chain reaction involving the $\mathrm{Cl}$ radical and produces phosgene $\left(\mathrm{COCl}_{2}\right)$ as one of the main organic products [30,40]:

$$
\begin{aligned}
& \mathrm{Cl}+\mathrm{CCl}_{3} \mathrm{O}_{2} \rightarrow \mathrm{CCl}_{3} \mathrm{O}+\mathrm{ClO} \\
& \mathrm{CCl}_{3} \mathrm{O} \rightarrow \mathrm{COCl}_{2}+\mathrm{Cl}
\end{aligned}
$$

The $\mathrm{ClO}$ species produces additional $\mathrm{Cl}$ radicals through a reaction with the $\mathrm{O}$ radicals [30,41]:

$$
\mathrm{O}+\mathrm{ClO} \rightarrow \mathrm{Cl}+\mathrm{O}_{2}
$$

The other major product is $\mathrm{Cl}_{2}$ which is formed by the reaction [41]:

$$
\mathrm{Cl}+\mathrm{Cl}+\mathrm{M} \rightarrow \mathrm{Cl}_{2}+\mathrm{M}
$$

The $\mathrm{CCl}_{3}$ species from reaction (9) can also be scavenged by $\mathrm{O}$ [42]:

$$
\mathrm{CCl}_{3}+\mathrm{O} \rightarrow \mathrm{COCl}_{2}+\mathrm{Cl}
$$

and by $\mathrm{N}$ [43]:

$$
\mathrm{CCl}_{3}+\mathrm{N} \rightarrow \mathrm{ClCN}+2 \mathrm{Cl}
$$

The apparent two-body rate constant for scavenging reaction (13) is $1.4 \times 10^{-9} \mathrm{~T}^{-1.1}$

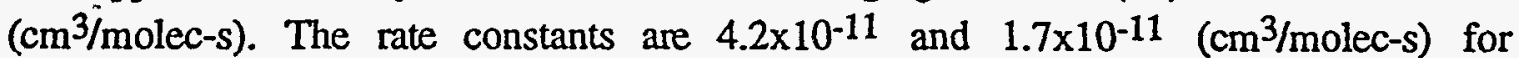
scavenging reactions (18) and (19), respectively. Because of the much larger density of $\mathrm{O}_{2}$ compared to $\mathrm{O}$ or $\mathrm{N}$, the scavenging of $\mathrm{CCl}_{3}$ by reactions (18) and (19) are therefore negligible compared to reaction (13) during processing in dry air.

Fig. 6 shows the results of experiments on electron beam and pulsed corona processing of $100 \mathrm{ppm}$ of $\mathrm{CCl}_{4}$ in dry air $\left(20 \% \mathrm{O}_{2} 80 \% \mathrm{~N}_{2}\right)$ at $25^{\circ} \mathrm{C}$. The pulsed corona reactor requires 1277 Joules/liter for $90 \%$ decomposition of $\mathrm{CCl}_{4}$, whereas the electron beam reactor requires only 20 Joules/liter to achieve the same level of decomposition.

An analysis of the rates of the reactions discussed above suggests that the rate limiting step in the decomposition of $\mathrm{CCl}_{4}$ is determined by the dissociative attachment of $\mathrm{CCl}_{4}$ to the thermalized electrons in the created plasma. The specific energy consumption for $\mathrm{CCl}_{4}$ removal is therefore determined by the specific energy consumption (or G-value) for creating electron-ion pairs. Table 2 shows the calculated G-values for the ionization 
processes (4)-(8). For electron beam processing of dry air, the ionization G-value corresponds to a specific energy consumption of $33 \mathrm{eV}$ per electron-ion pair produced. For pulsed corona processing, we calculate a specific energy consumption of around $1400 \mathrm{eV}$ per electron-ion pair, assuming an effective electron mean energy of $4 \mathrm{eV}$ in the discharge plasma. To first order, the calculated specific energy consumption for electron-ion pair production agrees very well with our experimentally observed specific energy consumption for $\mathrm{CCl}_{4}$ decomposition. The results shown in Fig. 6 demonstrate that for VOCs requiring copious amounts of electrons for decomposition, electron beam processing is much more energy efficient than electrical discharge processing.

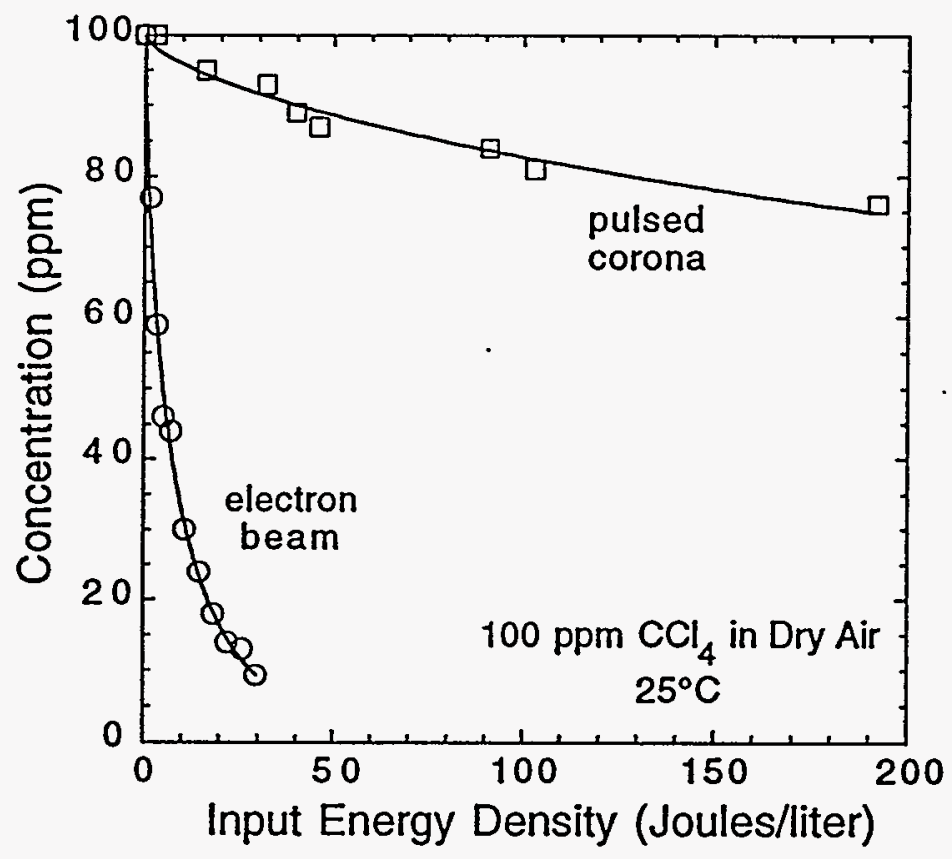

Fig. 6. Comparison between electron beam and pulsed corona processing of $100 \mathrm{ppm}$ of carbon tetrachloride in dry air at $25^{\circ} \mathrm{C}$.

After the concentration of $\mathrm{CCl}_{4}$ has decreased to a few tens of $\mathrm{ppm}$, the three-body attachment of thermal electrons to oxygen molecules [44]:

$$
\begin{aligned}
& \mathrm{e}+\mathrm{O}_{2}+\mathrm{O}_{2} \rightarrow \mathrm{O}_{2}^{-}+\mathrm{O}_{2} \\
& \mathrm{e}+\mathrm{O}_{2}+\mathrm{N}_{2} \rightarrow \mathrm{O}_{2}^{-}+\mathrm{N}_{2}
\end{aligned}
$$

becomes a significant electron loss pathway compared to reaction (9). The rate constants for reactions (20) and (21) are $\mathrm{k}_{(20)}=2.5 \times 10^{-30}$ and $\mathrm{k}_{(21)}=0.16 \times 10^{-30} \mathrm{~cm} / \mathrm{s}$, respectively. The attachment frequency of thermal electrons to $\mathrm{O}_{2}$ in dry air at atmospheric pressure is thus

$$
v_{\mathrm{O} 2}=\mathrm{k}_{(20)}\left[\mathrm{O}_{2}\right]^{2}+\mathrm{k}_{(21)}\left[\mathrm{N}_{2}\right]\left[\mathrm{O}_{2}\right] \approx 0.8 \times 10^{8} \mathrm{~s}^{-1}
$$


The attachment rate coefficient for thermal electrons to $\mathrm{CCl}_{4}$ is $\mathrm{k}_{(9)}=4 \times 10^{-7} \mathrm{~cm}^{3} / \mathrm{s}$. For $100 \mathrm{ppm} \mathrm{CCl}_{4}$, the attachment frequency to $\mathrm{CCl}_{4}$ is thus .

$$
v_{\mathrm{CCl} 4}=\mathrm{k}_{(9)}\left[\mathrm{CCl}_{4}\right] \approx 10^{9} \mathrm{~s}^{-1} \text {. }
$$

When the concentration of $\mathrm{CCl}_{4}$ is down to around $10 \mathrm{ppm}$, the electrons will attach to oxygen molecules as frequently as to $\mathrm{CCl}_{4}$ molecules.

Although the dominant pathway (dissociative electron attachment) for the initial decomposition of $\mathrm{CCl}_{4}$ is the same in electron beam and pulsed corona processing, the composition of the final products are not the same. In pulsed corona processing, a larger amount of $\mathrm{O}$ radicals is produced relative to the amount of electrons. Even though these $\mathrm{O}$ radicals contribute only a small fraction to the initial decomposition of $\mathrm{CCl}_{4}$, they do interact significantly with phosgene to change the composition of the final products [28,45]:

$$
\begin{aligned}
& \mathrm{O}+\mathrm{COCl}_{2} \rightarrow \mathrm{ClO}+\mathrm{COCl} \\
& \mathrm{COCl}+\mathrm{M} \rightarrow \mathrm{CO}+\mathrm{Cl}+\mathrm{M} \\
& \mathrm{O}+\mathrm{COCl} \rightarrow \mathrm{CO}_{2}+\mathrm{Cl}
\end{aligned}
$$

Our model for the decomposition mechanism predicts a difference in product yields between electron beam and pulsed corona processing at the minimum energy required for near complete decomposition of $\mathrm{CCl}_{4}$. For around $95 \%$ decomposition of $100 \mathrm{ppm} \mathrm{CCl}_{4}$ in dry air by electron beam processing, the final products consist of around $100 \mathrm{ppm} \mathrm{Cl}_{2}$ and $100 \mathrm{ppm} \mathrm{COCl}$. For the same level decomposition of $100 \mathrm{ppm} \mathrm{CCl}_{4}$ in dry air by pulsed corona processing, the final products consist of around $160 \mathrm{ppm} \mathrm{Cl}_{2}, 40 \mathrm{ppm} \mathrm{COCl}_{2}, 50$ ppm $\mathrm{CO}$ and $10 \mathrm{ppm} \mathrm{CO}_{2}$. Of course, with excessive energy deposition all the $\mathrm{COCl}_{2}$ would eventually be converted into $\mathrm{CO}_{\mathrm{x}}$ and $\mathrm{Cl}_{2}$. However, as noted in References [46] and [47], the $\mathrm{Cl}_{2}$ and $\mathrm{COCl}_{2}$ products can be easily removed from the gas stream; e.g. they dissolve and/or dissociate in aqueous solutions and combine with $\mathrm{NaHCO}_{3}$ in a scrubber solution to form $\mathrm{NaCl}$ [47].

Fig. 7 shows the results of experiments on electron beam and pulsed corona processing of $100 \mathrm{ppm}$ of methanol in dry air at $25^{\circ} \mathrm{C}$. The pulsed corona reactor requires 450 Joules/liter for $90 \%$ decomposition of methanol, whereas the electron beam reactor requires only around 15 Joules/liter to achieve the same level of decomposition. In this case, the electron beam method is more efficient because the decomposition proceeds mainly via a dissociative charge exchange reaction

$$
\mathrm{N}_{2}{ }^{+}+\mathrm{CH}_{3} \mathrm{OH} \rightarrow \mathrm{CH}_{3}{ }^{+}+\mathrm{OH}+\mathrm{N}_{2}
$$

The $\mathrm{OH}$ radicals resulting from the initial decomposition reaction (25) in turn may lead to additional decomposition of methanol via $\mathrm{OH}+\mathrm{CH}_{3} \mathrm{OH}$.

To verify that the primary decomposition during electron beam processing does not proceed through an oxidation pathway using $\mathrm{O}$ radicals, we performed the experiment using $\mathrm{N}_{2}$ as the background gas. As shown in Fig. 8, the specific energy consumption in dry air is almost identical to that in $\mathrm{N}_{2}$. 


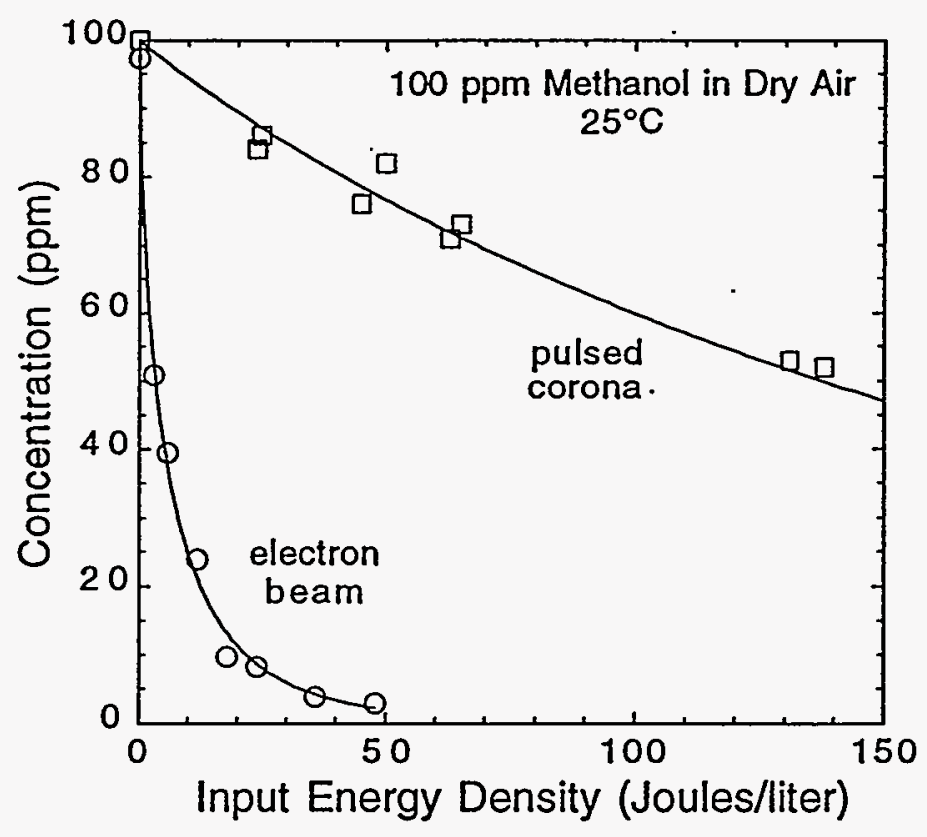

Fig. 7. Comparison between electron beam and pulsed corona processing of $100 \mathrm{ppm}$ of methanol in dry air at $25^{\circ} \mathrm{C}$.

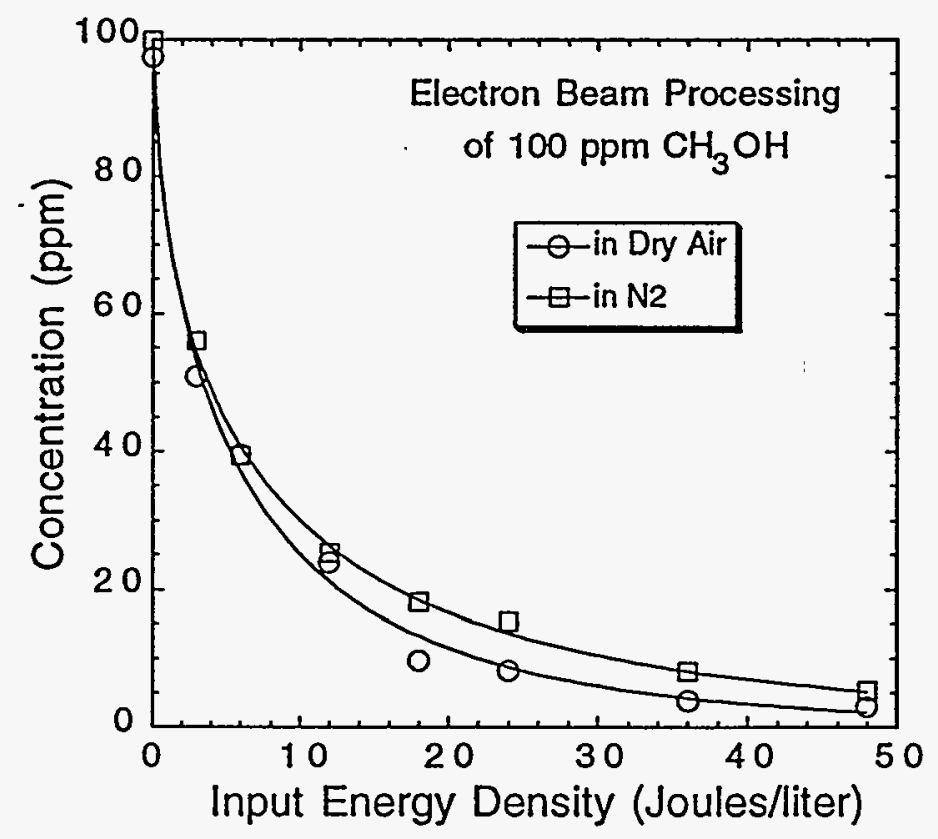

Fig. 8. Comparison between electron beam of $100 \mathrm{ppm}$ of methanol in dry air and electron beam processing of $100 \mathrm{ppm}$ of methanol in $\mathrm{N}_{2}$. Gas temperature is $25^{\circ} \mathrm{C}$. 


\section{ACKNOWLEDGMENTS}

This work was performed in part at Lawrence Livermore National Laboratory under the auspices of the U.S. Department of Energy under Contract Number W-7405-ENG-48, with support from the Advanced Energy Projects Division of the Office of Energy Research. The electron beam processing equipment was developed under a National Science Foundation SBIR grant, Contract Number III-9122767.

\section{REFERENCES}

[1] R. C. Slater and D. H. Douglas-Hamilton, J. Appl. Phys. 52, 5820 (1981).

[2] H. Scheytt, H. Esrom, L. Prager, R. Mehnert, and C. von Sonntag, in Non-Thermal Plasma Techniques for Pollution Control: Part B - Electron Beam and Electrical Discharge Processing, edited by B. M. Penetrante and S. E. Schultheis (SpringerVerlag, Heidelberg, 1993) pp. 91-102.

[3] S. M. Matthews, A. J. Boegel, J. A. Loftis, R. A. Caufield, B. J. Mincher, D. H. Meikrantz, and R. J. Murphy, Radiat. Phys. Chem. 42, 689 (1993).

[4] L. Bromberg, D. R. Cohn, M. Kock, R. M. Patrick, and P. Thomas, Phys. Lett. A 173, 293 (1993).

[5] M. Koch, D. R. Cohn, R. M. Patrick, M. P. Schuetze, L. Bromberg, D. Reilly and P. Thomas, Phys. Lett. A 184, 109 (1993).

[6] B. M. Penetrante, M. C. Hsiao, B. T. Merritt, G. E. Vogtlin, P. H. Wallman, A. Kuthi, C. P. Burkhart and J. R. Bayless, Phys. Lett. A (in press, 1996).

[7] H.-R. Paur, in Non-Thermal Plasma Techniques for Pollution Control: Part B Electron Beam and Electrical Discharge Processing, edited by B. M. Penetrante and S. E. Schultheis (Springer-Verlag, Heidelberg, 1993) pp. 77-90.

[8] M. C. Hsiao, B. T. Merritt, B. M. Penetrante, G. E. Vogtlin, and P. H. Wallman, J. Appl. Phys. 78, 3451 (1995).

[9] T. Yamamoto, K. Ramanathan, P. A. Lawless, D. S. Ensor, J. R. Newsome, N. Plaks, G. H. Ramsey, C. A. Vogel, and L. Hamel, IEEE Trans. on Ind. Appl. 28, 528 (1992).

[10] T. Yamamoto, P. A. Lawless, M. K. Owen, D. S. Ensor, and C. Boss, in NonThermal Plasma Techniques for Pollution Control: Part B - Electron Beam and Electrical Discharge Processing, edited by B. M. Penetrante and S. E. Schultheis (Springer-Verlag, Heidelberg, 1993) pp. 223-238.

[11] D. Evans, L. A. Rosocha, G. K. Anderson, J. J. Coogan, and M. J. Kushner, J. Appl. Phys. 74, 5378 (1993).

[12] L. A. Rosocha, G. K. Anderson, L. A. Bechtold, J. J. Coogan, H. G. Heck, M. Kang, W. H. McCulla, R. A. Tennant, and P. J. Wantuck, in Non-Thermal Plasma Techniques for Pollution Control: Part B - Electron Beam and Electrical Discharge Processing, edited by B. M. Penetrante and S. E. Schultheis (Springer- 
Verlag, Heidelberg, 1993) pp. 281-308.

[13] W. C. Neely, E. I. Newhouse, E. J. Clothiaux, and C. A. Gross, in Non-Thermal . Plasma Techniques for Pollution Control: Part B -Electron Beam and Electrical Discharge Processing, edited by B. M. Penetrante and S. E. Schultheis (SpringerVerlag, Heidelberg, 1993) pp. 309-320.

[14] E. I. Newhouse, W. C. Neely, E. J. Clothiaux, and J. W. Rogers, in ACS Symposium on Emerging Technologies in Hazardous Waste Management VI, pp. 207-210.

[15] E. J. Clothiaux, J. A. Koropchak, and R. R. Moore, Plasma Chem. Plasma Process. 4, 15 (1984).

[16] M. E. Fraser, D. A. Fee, and R. S. Sheinson, Plasma Chem. Plasma Process. 5, 163 (1985).

[17] M. E. Fraser and R. S. Sheinson, Plasma Chem. Plasma Process. 6, 27 (1986).

[18] S. Masuda, in Non-Thermal Plasma Techniques for Pollution Control: Part B Electron Beam and Electrical Discharge Processing, edited by B. M. Penetrante and S. E. Schultheis (Springer-Verlag, Heidelberg, 1993) pp. 199-210.

[19] T. Oda, T. Takahashi, H. Nakano, and S. Masuda, in Proceedings of the 1991 IEEE Industrial Application Society Meeting (Dearborn, MI, September/October 1991) pp. 734-739.

[20] A. Czernichowski and H. Lesueur, in Proceedings of the 10th International Symposium on Plasma Chemistry (Bochum, Germany, 1991).

[21] A. Czernichowski and T. Czech, in Proceedings of the 3rd International Symposium on High-Pressure Low-Temperature Plasma Chemistry (Strasbourg, France, 1991).

[22] L. J. Bailin, M. E. Sibert, L. A. Jonas, and A. T. Bell, Environ. Sci. Tech. 9, 254 (1975).

[23] W. L. Morgan and B. M. Penetrante, Comp. Phys. Comm. 58, 127-152 (1990).

[24] B. M. Penetrante and J. N. Bardsley, J. Appl. Phys. 66, 1871-1874 (1989).

[25] R. J. Kee, F. M. Rupley and J. A. Miller, "Chemkin-II: A FORTRAN Chemical Kinetics Package for the Analysis of Gas Phase Chemical Kinetics," Sandia National Laboratories Report No. SAND89-8009B UC-706 (April 1992).

[26] B. Eliasson and U. Kogelschatz, J. Phys. B: At. Mol. Phys. 19, 1241 (1986).

[27] B. M. Penetrante, in Non-Thermal Plasma Techniques for Pollution Control - Part A: Overview, Fundamentals and Supporting Technologies, B. M. Penetrante and S. E. Schultheis, Eds. (Springer-Verlag, Berlin Heidelberg, 1993) pp. 65-90.

[28] J. T. Herron, J. Phys. Chem. Ref. Data 17, 967 (1988).

[29] J. A. Davidson, H. I. Schiff, T. J. Brown, C. J. Howard, J. Chem. Phys. 69, 4277 (1978). 
[30] R. Atkinson, D. L. Baulch, R. A. Cox, R. F. Hampson, Jr., J. A. Kerr, J. Troe, J. Phys. Chem. Ref. Data 21, 1125-1568 (1992).

[31] Y. Itikawa, M. Hayashi, A. Ichimura, K. Onda, D. Sakimoto, K. Takayanagi, M. Nakamura, H. Nishimura and T. Takayanagi, J. Phys. Chem. Ref. Data 15, 985 (1986).

[32] Y. Itikawa, A. Ichimura, K. Ondaz, K. Sakimoto, K. Takayanagi, Y. Hatano, M. Hayashi, H. Nishimura and S. Tsurubuchi, , J. Phys. Chem. Ref. Data 18, 23 (1989).

[33] A. A. Christodoulides and L. G. Christophorou, J. Chem. Phys. 54, 4691 (1971).

[34] J. A. Ayala, W. E. Wentworth and E. C. M. Chen, J. Phys. Chem. 85, 3989 (1981).

[35] D. L. Albritton, Atom. Data Nucl. Data Tables 22, 1 (1978).

[36] F. Danis, F. Caralp, B. Veyret, H. Loirat, R. Lesclaux, Int. J. Chem. Kinet. 21, 715 (1989).

[37] T. Ellermann, Chem. Phys. Lett. 189, 175 (1992).

[38] F. Danis, F. Caralp, M. T. Rayez, R. Lesclaux, J. Phys. Chem. 95, 7300-7307 (1991).

[39] F. F. Fenter, P. D. Lightfoot, J. T. Niiranen, D. Gutman, J. Phys. Chem. 97, 3135320 (1993).

[40] J. J. Russell, J. A. Seetula, D. Gutman, F. Danis, F. Caralp, P. D. Lightfoot, R. Lesclaux, C. F. Melius, S. M. Senkan, J. Phys. Chem. 94, 3277 (1990).

[41] D. L. Baulch, J. Duxbury, S. J. Grant, D. C. Montague, J. Phys. Chem Ref. Data 10, Suppl. 1,1-1 (1981).

[42] J. T. Herron, J. Phys. Chem. Ref. Data 17, 967 (1988).

[43] S. C. Jeoung, K. Y. Choo and S. W. Benson, J. Phys. Chem. 95, 7282 (1991).

[44] L. M. Chanin, A. V. Phelps and M. A. Biondi, Phys. Rev. 128, 219 (1962).

[45] W.-D. Chang and S. M. Senkan, Environ. Sci. Tech. 23, 442 (1989).

[46] D. Evans, L. A. Rosocha, G. K. Anderson, J. J. Coogan and M. J. Kushner, J. Appl. Phys. 74, 5378 (1993).

[47] R. M. Patrick and K. Hadidi, An Electron Beam Plasma System for Halogenated Hydrocarbon Vapor Destruction, Preprint No. 95-WP77B.04, 88th Annual Meeting \& Exhibition of the Air \& Waste Management Association, San Antonio, TX (18-23 June 1995). 


Technical Information Department. Lawrence Livermore National Laboratory University of California . Livermorc, California 94551

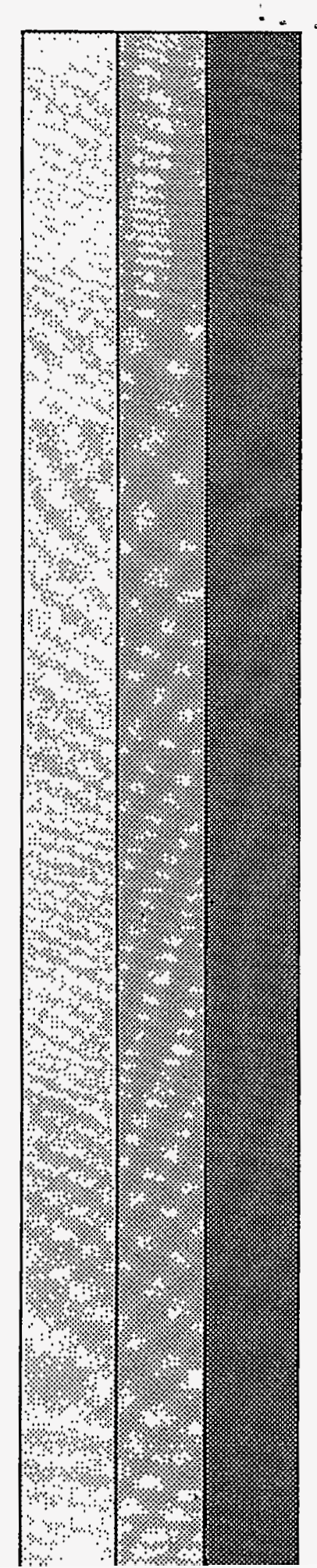

